\title{
Equoterapia: um método terapêutico capaz de renovar vidas
}

\author{
Daniela Teles \\ Instituto Federal de Educação, Ciência e Tecnologia do Rio Grande do Sul- Campus Sertão \\ (danielateles20@gmail.com) \\ Michelen De Nardi Teixeira \\ Instituto Federal de Educação, Ciência e Tecnologia do Rio Grande do Sul- Campus Sertão \\ (michelendteixeira@hotmail.com) \\ Marcos Antonio de Oliveira \\ Instituto Federal de Educação, Ciência e Tecnologia do Rio Grande do Sul- Campus Sertão \\ (marcos.oliveira@sertao.ifrs.edu.br)
}

\begin{abstract}
Resumo: A equoterapia é uma técnica multidisciplinar que utiliza o cavalo como recurso educacional, psicoterapêutico e esportivo, reabilitando pessoas com especificidades. É indicado a indivíduos com lesões neuromotoras de origem medular, patologias ortopédicas congênitas ou adquiridas por acidentes diversos, necessidades educativas especiais, distúrbios evolutivos, comportamentais e de aprendizagem. Este método proporciona ao seu praticante bem-estar, inclusão social, além de ter resultados favoráveis na área da saúde. No Instituto Federal de Educação, Ciência e Tecnologia do Rio Grande do Sul - campus Sertão foi implantado o projeto "Atividades de equoterapia para os municípios de Sertão e microrregião", visto que esta região apresenta uma carência no atendimento de indivíduos com necessidades especificas. Atualmente, são atendidos em torno de cem praticantes por semana, oriundos dos municípios de Coxilha, Getúlio Vargas, Sertão, Vila Lângaro. Para que a terapia seja desenvolvida, é necessária uma equipe mínima, composta de fisioterapeuta, fonoaudiólogo, psicólogo, pedagogo, profissional de educação física e equitador.
\end{abstract}

Palavras chave: Terapia; Cavalo; Especificidade.

\section{Equotherapy: a therapeutic method able to renew lives}

Abstract: Equine therapy is a multidisciplinary technique that uses the horse as an educational, psychotherapeutic and sports resource, rehabilitating people with particularities. It is recommended to individuals with neuromotor injuries of spinal origin, congenital or acquired orthopedic pathologies acquired by diverse accidents, special learning needs, and evolutionary, behavioral and learning disorders. This method provides to its practitioner well-being, social inclusion, besides having favorable results in the health area. In the Federal Institute of Education, Science and Technology of Rio Grande do Sul - Campus Sertão, the project "Equine therapy activities for the cities of Sertão and microregion" was implemented as this region presents a lack of care for individuals with specific needs. Currently, around one hundred practitioners are attending, per week, from the cities of Coxilha, Getúlio Vargas, Sertão, Vila Lângaro. In order to develop the therapy, a minimum team composed of physiotherapist, speech therapist, psychologist, pedagogue, physical education professional and equitator is required.

Keywords: Therapy; Horse; Physical particularity. 
A equoterapia é um método terapêutico e multidisciplinar que utiliza o cavalo como promotor de benefícios na saúde, na educação e na equitação de pessoas com especificidades (ANDE/BRASIL,1989). A efetividade desta prática, somada à participação da família e de outras entidades, proporciona a interação social e o bem-estar do praticante.

Buscando suprir uma carência no atendimento alternativo de indivíduos com necessidades especificas, de forma humanitária, e possibilitando atingir classes sociais menos favorecidas, foi criado no Instituto Federal de Educação, Ciência e Tecnologia do Rio Grande do Sul - campus Sertão, o projeto "Atividades de equoterapia para os municípios de Sertão e microrregião" (Figura 1).

Figura 1: Logomarca do Centro de Equoterapia do Cavalo Crioulo.

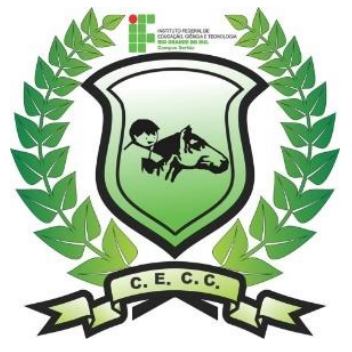

Fonte: Oliveira, Marcos A. 2012.

$\mathrm{Na}$ realização do projeto, foi construído o Centro de Equoterapia do Cavalo Crioulo (CECC) (Imagem 1), local onde são atendidos semanalmente seis grupos de praticantes, sendo eles: as Associações de Pais e Amigos dos Excepcionais (APAEs), dos municípios de Sertão, de Getúlio Vargas e de Coxilha, o Centro Integrado Renascer (CIR), o Núcleo Integrado de Atendimento ao Educando (NIAE), de Getúlio Vargas e o Grupo Gota de Amor, de Vila Lângaro, totalizando aproximadamente cem sessões semanais.

Imagem 1: Instalações do CECC.

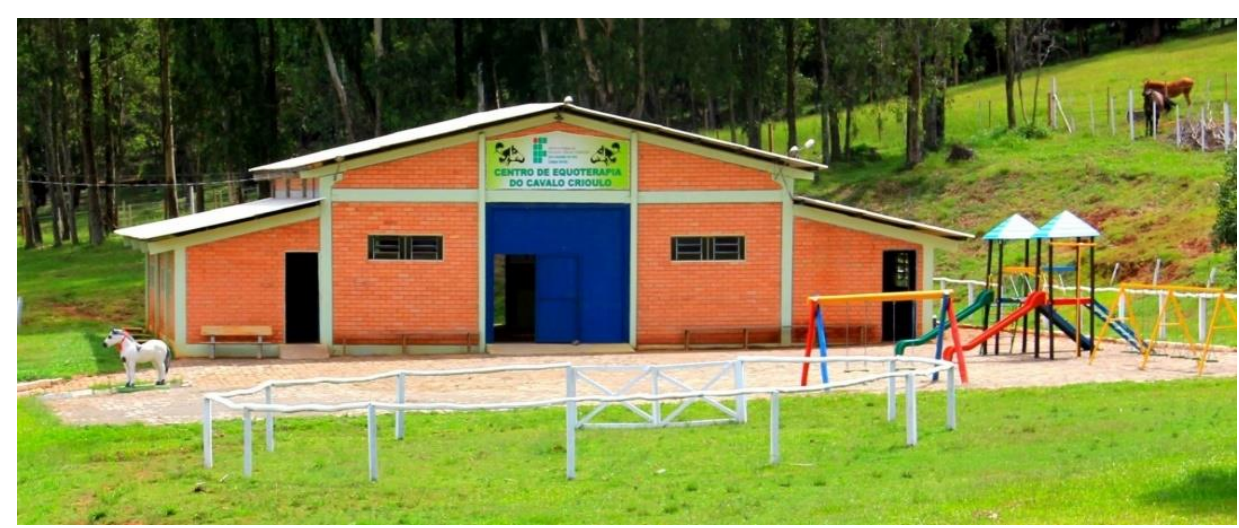

Fonte: Oliveira, Marcos A. 2012. 
Os municípios conveniados ao CECC são responsáveis por disponibilizar para o atendimento uma equipe mínima de profissionais, composta de fisioterapeuta, fonoaudiólogo, psicólogo, pedagogo, profissional de educação física e equitador. Por sua vez, o Centro é responsável por fornecer auxiliar guia (sendo estes bolsistas, estagiário, voluntários e professores que participam do programa), animais treinados (e livres de cansaço), contando com um rebanho de seis cavalos (revezados durante os dias de trabalho) e um pônei, que é usado para os primeiros contatos entre o animal e o praticante (Imagem 2). O CECC disponibiliza também instalações, como picadeiro (externo e interno), áreas de socialização em meio à natureza, salas (de aula, de reuniões e de convivência), banheiros, cocheiras, áreas de pastejo para os animais, além de toda a estrutura necessária para o desenvolvimento da técnica.

$O$ atendimento equoterápico somente pode ser desenvolvido mediante parecer favorável em avaliação (médica, psicológica e fisioterápica), em diversas patologias, como, por exemplo, autismo, paralisia cerebral, síndrome de Down, hiperatividade, retardo mental, distúrbios psicológicos, entre outros.

Imagem 2: Seção de equoterapia.

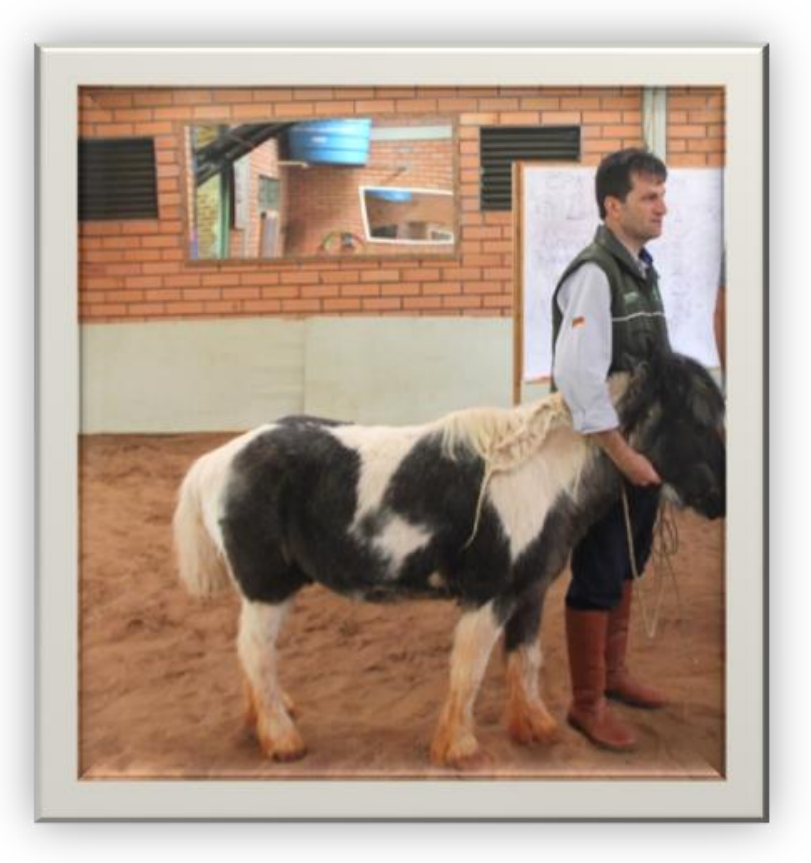

Fonte: Oliveira, Marcos A. 2017.

O equino, locomovendo-se, disponibiliza ao praticante um movimento tridimensional, para frente e para trás, para cima e para baixo e de um lado para outro (Imagem 3). Este é transmitido ao cavaleiro pelo contato de seu corpo com o 
animal, gerando oscilações mais complexas de rotação e translação. Esta ação se assemelha a realizada pelo humano quando caminha, sendo o equídeo o único animal que consegue reproduzir a ação retratando imagens cerebrais sequenciais e impulsos nervosos importantes para reabilitação.

Imagem 3: Movimento Tridimensional - Cavalo X Homem.

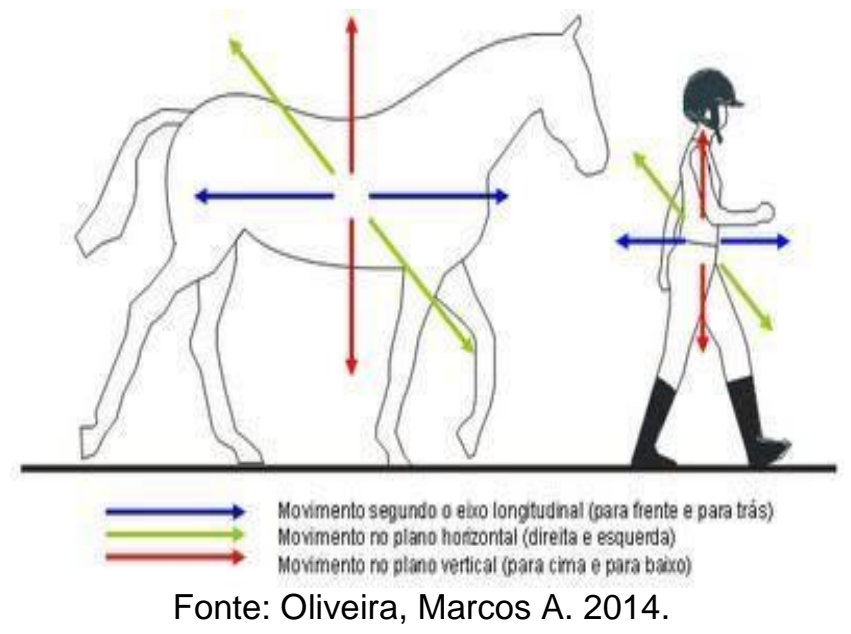

É valido ressaltar que a prática traz inúmeros benefícios, como, por exemplo, equilíbrio e postura, desenvolvimento da coordenação motora, estimulação da sensibilidade (tátil, visual e auditiva), melhora do tônus muscular, aumento da força muscular, facilita a integração social, desenvolve a motricidade fina, estimula o funcionamento dos órgãos internos, aumenta a autoestima, a autoconfiança e o afeto (devido ao contato com o animal, através de escovação, banho e demonstrações de carinho), promovendo a sensação de bem-estar (Imagem 4).

Imagem 4: Contato entre animal e praticantes.

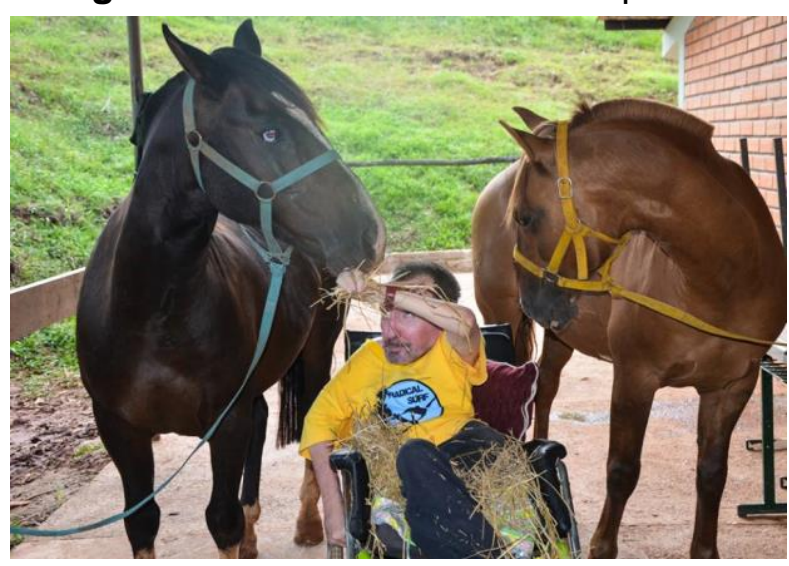

Fonte: Oliveira, Marcos A.. 2016.

Diante do exposto e através de depoimentos de pais e familiares, percebe-se que a equoterapia é uma técnica que contribui significativamente para melhoria da qualidade de vida dos praticantes, diferindo-se de outros métodos. 
A equoterapia contribui para avanços nos quadros clínicos e nos relacionamentos sociais dos praticantes. Além disso, também proporciona evolução pessoal e profissional nos colaboradores, por meio do envolvimento simultâneo dos grupos de profissionais, de praticantes e de acadêmicos, estimulando assim o desenvolvimento contínuo do projeto.

\section{Referência:}

Associação Nacional de Equoterapia - Ande/Brasil,1989. O Método. Disponível em: <http://equoterapia.org.br/articles/index/article_detail/142/2022> Acesso em: 31 mar. 2017. 